\title{
MANIFESTACIONES RUPESTRES EN EL CAMPO VOLCÁNICO PALI AIKE (CUENCA DEL RÍO GALLEGOS, SANTA CRUZ, ARGENTINA)
}

\author{
LILIANA M. MANZI* Y FLAVIA CARBALLO MARINA*
}

\begin{abstract}
RESUMEN
Se presenta información recuperada en sitios con registros de manifestaciones rupestres comparables al "Estilo Río Chico" (sensu Bate 1970, 1971) localizados en la sector medio e inferior de la cuenca del río Gallegos. Se analizan las frecuencias y diversidad de motivos, la selección de soportes y el estado de conservación de las pinturas. Luego, esta evidencia es integrada en una escala suprarregional dentro del Campo Volcánico Pali Aike (Argentina) y en relación con el río Chico y la región de Última Esperanza (Chile), con el objeto de evaluar procesos de ocupación del espacio y reconocer estrategias de circulación e interacción poblacional. Para ello fueron consideradas la dispersión de clases de motivos rupestres y las series tonales en que fueron ejecutados.
\end{abstract}

PALABRAS CLAVE: diversidad de motivos, frecuencias de motivos, soportes rocosos, espacio regional, espacio suprarregional.

\section{ROCK ART IN THE PALI AIKE VOLCANIC FIELD (RÍO GALLEGOS BASIN, SANTA CRUZ, ARGENTINA)}

\section{ABSTRACT}

Rock art data related to the "Estilo Río Chico" (sensu Bate 1970, 1971) from sites located along the Gallegos river basin is introduced. Frequency and diversity of motifs, the selection of supports and the conservation status of the paintings are analized. Then, this evidence is integrated within a supra-regional scale in the Pali Aike Volcanic Field (Argentina) and in relation to the Chico River and the region of Ultima Esperanza (Chile), in order to evaluate processes of landscape occupation and recognize movement and interaction strategies of population. For this were considered the dispersion of rock art classes and tonal series that were executed.

KEY WORDS: motifs diversity, motifs frequencies, supports rocky; regional space, suprarregional space.

IMHICIHU-CONICET, Saavedra 15, Piso 5․ 1083 Ciudad Autónoma de Buenos Aires. Argentina. lm_manzi@yahoo.com.ar.

* Universidad Nacional de la Patagonia Austral. Unidad Académica Río Gallegos. Campus Universitario, Avda. Gregores y Piloto Lero Rivera s/n. (9400) Río Gallegos, Santa Cruz. Argentina. fcarballo@uarg.unpa.edu.ar. 


\section{INTRODUCCIÓN}

En proximidades de las cuencas de los ríos Gallegos y Chico, provincia de Santa Cruz (Argentina) fueron registradas pinturas rupestres, las que a partir de criterios iconográficos pueden ser englobadas dentro del denominado "Estilo Río Chico", definido por Bate $(1970,1971)$ en la región de Última Esperanza (Chile). Sus indicadores son la alta frecuencia de motivos geométricos simples, además de algunos tridígitos, manos en negativos y positivos, zoomorfos y antropomorfos, en ambos casos muy esquemáticos. Las series tonales comprenden, mayoritariamente, los tonos rojos que presentan ciertas variaciones (Hernández Llosas et al. 1999; Campan et al. 2007; Massone 1982, entre otros), aunque se han registrado unos pocos motivos en color negro y blanco.

En ausencia de dataciones de motivos y/o mezclas pigmentarias se tienen expectativas de que las expresiones pictográficas pudieran corresponder a registros de ocupaciones tardías en el campo volcánico Pali Aike -CVPA-, ubicadas en torno a los últimos $2000 \mathrm{AP}$, dada su relación de proximidad con depósitos arqueológicos fechados dentro de ese rango temporal, tales como La Carlota, cueva 1 (Campan et al. 2007), Potrok Aike, cueva 1 (Gómez Otero 1993); Río Chico 1 (Massone 1985) y Cañadón Leona, alero 5 (Prieto et al. 1998).

Las manifestaciones rupestres fueron ejecutadas sobre las paredes basálticas de la Unidad 1 del CVPA (sensu D'Orazio et al. 2000), su distribución comprende tanto al sector chileno (Bate 1970, 1971; Gallardo 2009; Massone 1982), como al argentino (Campan et al. 2007; Gómez Otero 1983-85, 1988, 1989-90; Hernández Llosas et al. 1999; Molina 1972; Manzi et al. 2010; Sanguinetti de Bórmida 1981). A esas investigaciones previas, en este trabajo, se agregan otros sitios que fueron detectados recientemente en el sector medio e inferior de la cuenca del río Gallegos.

En la presentación de estos sitios se discriminan las frecuencias y diversidad de motivos, la selección de soportes y el estado de conservación de las pinturas. Luego, esta información es integrada y discutida en una escala suprarregional, dentro del CVPA, en relación con el río Chico y la región de Última Esperanza. Para ello son consideradas las clases de motivos rupestres, su dispersión y/o conti- nuidad dentro del espacio plástico de representación, las alturas en que se distribuyen y las series tonales en que fueron ejecutadas.

\section{EL CAMPO VOLCÁNICO PALI AIKE}

El CVPA abarca unos $7.500 \mathrm{~km}^{2}$ extendiéndose desde el río Coyle (provincia de Santa Cruz, Argentina) hasta las cercanías de la costa del estrecho de Magallanes (Última Esperanza, Chile) (Corbella 2002). Se trata de una unidad geomorfológica en cuya génesis intervinieron distintos episodios de vulcanismo fisural que evidencia diferentes aportes de materiales volcánicos y sustentan diversas cronologías (Skewes 1978; Meglioli 1992; Corbella 2002). Estas dos características fueron las que permitieron diferenciar unidades denominadas 1,2 y 3 (sensu D'Orazio et al. 2000).

La cuenca del río Gallegos, con nacientes en la cordillera, discurre por un amplio valle fluvial que atraviesa el CVPA de oeste a este por su extremo septentrional, recorriendo el ambiente de estepa para desembocar en el océano Atlántico. En tanto sus tributarios, los ríos Gallegos Chico, La Carlota y Robles ingresan en el interior del mismo siguiendo sentido sur-norte, mientras que el río Chico lo hace de este a oeste corriendo encajonado entre coladas basálticas (Figura 1).

Las mesetas basálticas que conforman los soportes naturales sobre las que se plasmaron los motivos rupestres corresponden a la Unidad 1 (D'Orazio et al. 2000), alcanzando alturas que oscilan entre los 50 y 200 m snm, en las que pueden señalarse tres segmentos topográficamente diferenciables: a) las cumbres, de forma básicamente plana, contienen algunas lagunas y depresiones menores; b) las laderas, conforman frentes abruptos -entre $40^{\circ} \mathrm{y}$ $90^{\circ}$ - que caen sobre el nivel inferior y c) las bases, en la que se acumulan bloques desprendidos de la colada y otros aportes sedimentarios, con pendientes comprendidas entre los $20^{\circ}$ y $10^{\circ}$.

Entre los soportes seleccionados se diferencian espacios planos con alta exposición a la intemperie, que muestran cierta continuidad -paredes y paredones-, y áreas reparadas de menor extensión, que adoptan las formas de abrigos profundos -cuevas- o de salientes rocosas -aleros-.

La distribución de localizaciones con pinturas rupestres indica que son pocos los sitios, detectados 


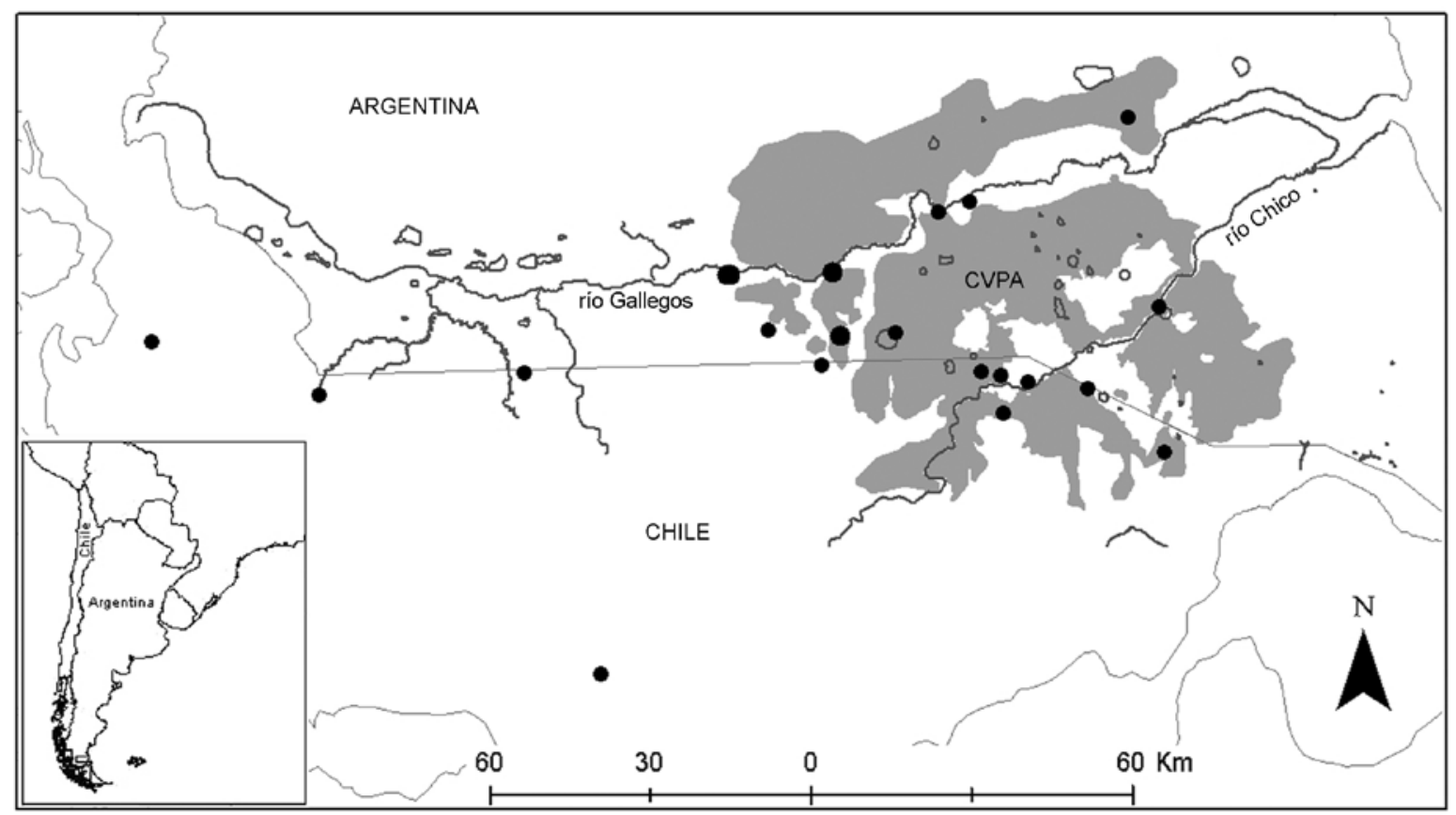

Fig. 1. Unidad 1 del Campo Volcánico Pali Aike: distribución de sitios con pinturas rupestres.

hasta el presente, que se ubican en el interior del CVPA. Esta situación puede atribuirse, entre otras cuestiones, a las estrategias de muestreo implementadas por los distintos equipos de investigación que trabajaron el mismo.

La presentación de la información arqueológica es organizada tomando en consideración el límite internacional, diferenciando los sectores chileno y argentino del CVPA (Figura 1). En el sector chileno, Bate (1970, 1971) realizó prospecciones que dieron por resultado el hallazgo de manifestaciones rupestres cuya recurrencia de diseños, a pesar de sus variantes regionales, le permitieron definir el "Estilo Río Chico". Con posterioridad, dado su carácter predominantemente geométrico y la simplicidad de los motivos ejecutados fueron incluidos por Massone (1982) dentro del "estilo geométrico". Estas y sucesivas investigaciones permitieron constatar que las representaciones comprenden motivos geométricos simples -abstractos lineales tales como trazos-, geométricos complejos -abstractos que no tienen referentes en la actualidad-, puntiformes abstractos y eventualmente zoomorfos, además de antropomorfos, tridígitos y manos en negativo y positivo (Bate 1970, 1971; Campan et al. 2007; Gómez Otero
1983-85, 1988, 1989-90; Hernández Llosas et al. 1999, Massone 1982; Molina 1972; Sanguinetti de Bórmida 1981).

En este trabajo, a partir de la consulta bibliográfica y en una escala regional y suprarregional, son comparados los registros de pinturas rupestres obtenidos recientemente por nosotras con los efectuados anteriormente. Sin embargo, surgieron algunos inconvenientes al momento de sistematizar la información, dada la falta de una terminología común entre los autores para dar cuenta de la diversidad de motivos observada. Esto llevó a que las referencias a las distintas clases de diseños fueran unificadas mediante denominaciones que aluden a los rasgos más simples de sus formas.

Por su parte, la recurrente falta de referencias a las frecuencias de motivos registrados, a las alturas alcanzadas en su distribución -a partir del nivel del suelo actual- y a las dimensiones de los soportes, las comparaciones fueron realizadas sobre la base de: la presencia/ausencia de clases de motivos (Ver Tablas 1 y 2), las características de las laderas basálticas y de las series tonales representadas (Ver a continuación).

En el sector chileno del CVPA (Tabla 1), al sureste de la laguna Blanca, se localiza el Cañadón 
Leona -CL-, donde Bate (1970) señala que las manifestaciones rupestres están distribuidas en distintas clases de reparos -paredes y aleros-. Posteriormente, Prieto et al. (1998) realizaron un relevamiento detallado de las pinturas señalando que el alero 3 es el lugar que presenta la mayor concentración de motivos. Del conjunto identificado se destaca la abundancia de antropomorfos, uno de ellos ejecutado en color negro, al igual que un tridígito $y$, un motivo -que no es posible determinar a partir de la publicación del calco- en tono amarillo pálido. Además, de bicromías ejecutadas con trazos rojos y negros.

En la confluencia de los ríos Rubens y Turbio se encuentra Morro Chico -MC- en donde fueron registradas pinturas en dos paredes y un alero (Bate 1970). Más tardíamente, se halló un colgante que podría corresponder a un contexto de inhumación decorado con trazos paralelos semejantes a los diseños rupestres (Prieto 1984).

En la margen sur del río Chico, en Ush Aike -UA- se registra un antropomorfo blanco y un arco bicromo -rojo y negro-. Cerca del río, se ubica la cueva Fell -F- con manifestaciones rupestres y a un kilómetro al este, en el Locus 1 -L1- Bate (1970) menciona la existencia de unos pocos trazos.

Los motivos existentes a una distancia intermedia entre Fell y el casco de la estancia Brazo Norte -que en la publicación de 1970 carece de nombre- parecen corresponder al sitio Río Chico 0 -RC0- (Bate 1971). Se trata de varias agrupaciones menores que fueron ejecutadas aprovechando los soportes adecuados para su producción.

A unos $2 \mathrm{~km}$ de la estancia Brazo Norte hay motivos distribuidos a lo largo de una extensa barda del río Chico, sitio Río Chico 1 -RC1- con concentraciones más o menos discretas de pinturas en la que sobresale un círculo concéntrico blanco (Bate 1970). A poco menos de $1 \mathrm{~km}$ aguas abajo se encuentra Río Chico 2 -RC2- registrando un puntiforme en el que alternan las series tonales roja y negra. Mientras que, el sitio Río Chico 5 -RC5- muestra un negativo de mano ejecutado en blanco y el sitio Río Chico 6 -RC6- pequeños antropomorfos esquemáticos (Bate 1971).

También en relación con río Chico, en el paraje Corrales de Indios -RGC-se registraron dos paredes con unos pocos motivos ejecutados en rojo (Bate 1971). Recientemente, un relevamiento realizado a lo largo de $12 \mathrm{~km}$ aguas arriba permitió identificar un total de 20 sitios, entre los que se incluyen los ya publicados (Gallardo 2009).

La Laguna Timone 2 -LT2- es un reparo rocoso con pinturas en la parte central del techo, a unos $3 \mathrm{~m}$ de altura. Mientras que, en la pared oeste y a escasa altura sobre el nivel del suelo hay otras agrupaciones de motivos. Asimismo, se menciona el registro de motivos rupestres en Laguna Timone 3 -LT3- (Massone 1982).

En Laguna Sota 1 -LSo1- las manifestaciones rupestres se encuentran repartidas en aleros dispuestos a lo largo de la pared del cráter que contiene a la laguna. Los motivos se ubican entre los 0,35 y $1,85 \mathrm{~m}$, y están distribuidos en tres grandes paneles que se extienden a lo largo de unos $200 \mathrm{~m}$. En este conjunto se destaca una bicromía en tonos rojo y ocre que por su morfología puede ser clasificada como indeterminada (Massone 1982:77, Figura 2).

En el alero Rose Aike 2 -RA2- motivos aislados en tono rojo se disponen entre los 0,65 y $1,05 \mathrm{~m}$, mientras que en el Rose Aike 3 -RA3- las pinturas se ubican entre los 0,24 y 1,27 m y distribuidas entre un alero y una cueva de pequeñas dimensiones. Por otra parte, en un abrigo semejante al anterior se observó un motivo aislado en el techo a $1 \mathrm{~m}$ de altura (Massone 1982).

En el brazo noroeste del río Chico fueron identificados los sitios Cañadón Seco 2 -CS2-, destacándose un arco bicromo -rojo y negro- que alcanza alturas comprendidas entre los 0,19 y 1,57 m, y Cañadón Seco 4 -CS4- donde los motivos se ubican desde el nivel del piso hasta los $0,93 \mathrm{~m}$ (Massone 1982).

Un conjunto de bloques sueltos son los soportes de las manifestaciones rupestres identificadas en Laguna Los Tábanos 1 -LLT1-, distribuidas en torno a los 0,37 y 0,66 m de altura (Massone 1982). En el alero Juni Aike 4 -JA4- las pinturas se disponen sobre las superficies más planas que ofrece el paredón de la colada con distancias al piso que varían entre los 1,20 y 2 m (Gómez Otero 1988, 1989-90).

En Última Esperanza, en el faldeo norte del Cerro Benítez se encuentran algunas cuevas y aleros con expresiones rupestres-Cerro Benítez 1 a 5 (CB1 a CB5)- ubicadas entre los 0,55 y 2 m. Cabe mencionar que, en Cerro Benítez 5 -CB5- hay un motivo de coloración parda que podría corresponder a un tono negro decolorado y tratarse de un trazo simple (Massone 1982: Figura 3). 


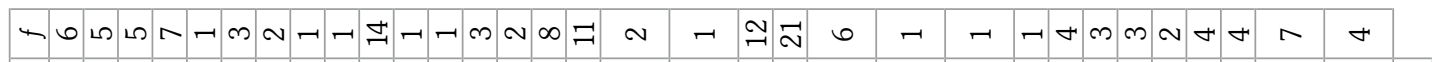

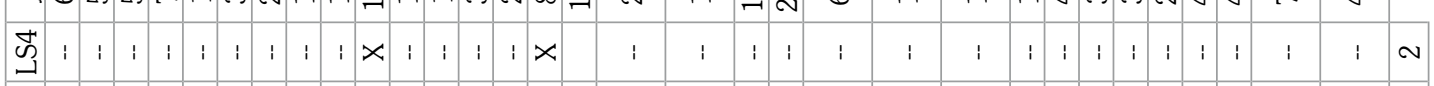

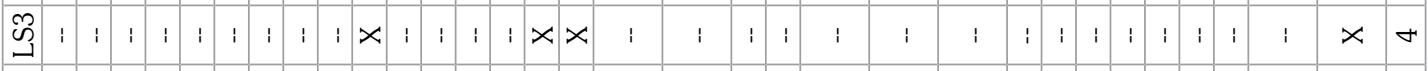

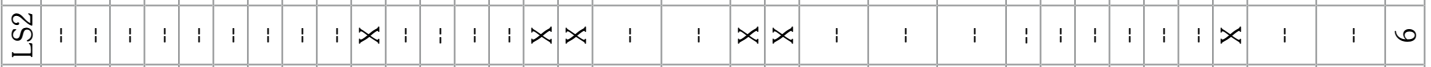

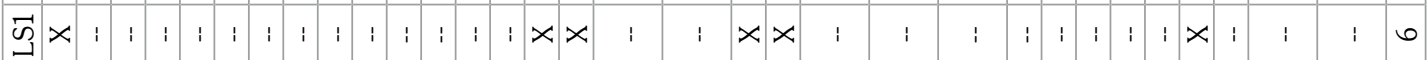

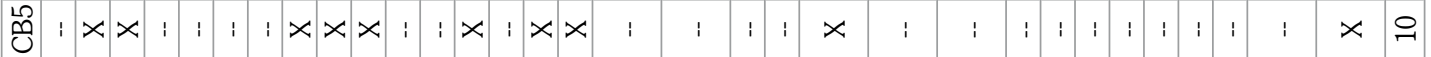
苍 满

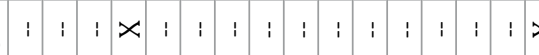

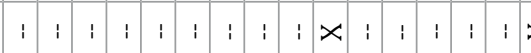

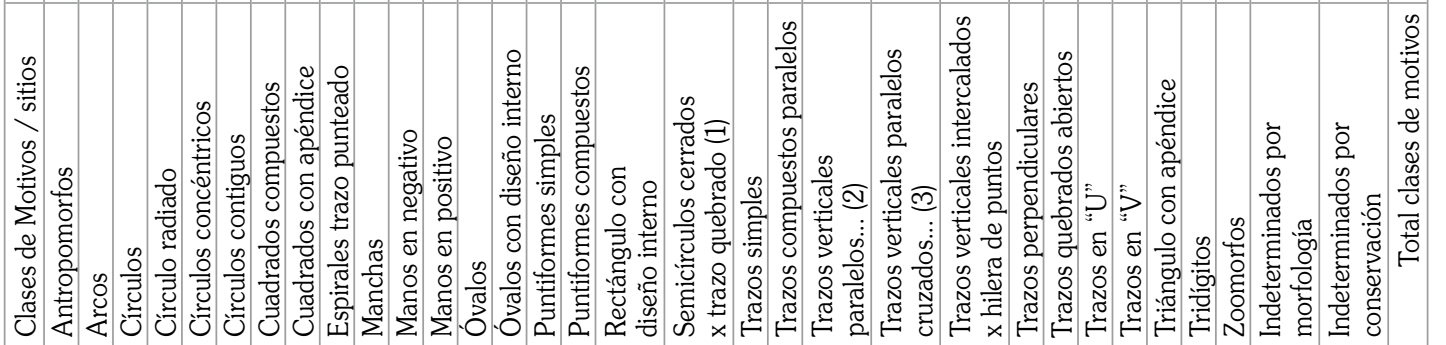


En el alero Lago Sofía 1 -LS1- los motivos se sitúan en la parte superior de la pared aprovechando los planos favorables del soporte (sensu Bate 1971). El conjunto de Lago Sofía 2 -LS2- está constituido por motivos pertenecientes a la serie tonal roja sobre cuatro grandes bloques desprendidos del cerro. En Lago Sofía 3 -LS3- y Lago Sofía 4 -LS4- los motivos fueron ejecutados en dos bloques aislados y están localizados entre los 0,63 y 0,80 m de altura (sensu Massone 1982).
En el sector argentino del CVPA (Tabla 2), en la margen norte del río Gallegos, Molina (1972) relevó el Abrigo Pintado de Güer Aike -APGA-, destacando la presencia de dos positivos de manos en color negro y un negativo de mano en la serie tonal roja. Mientras que, en la margen sur localizó el Abrigo de los Pescadores y la Gruta Pintada de Las Buitreras -GPLB-.

En esa misma margen se encuentran Las Buitreras, Cueva II y III (Sanguinetti de Bórmida

Tabla 2. Presencia/Ausencia de motivos rupestres en el sector argentino del CVPA.

\begin{tabular}{|c|c|c|c|c|c|c|c|c|}
\hline Clases de Motivos / sitios & APGA & APMA & LB2 & PAC1 & PAA1 & ARB & MCh 1-8 & $f$ \\
\hline Antropomorfos & -- & $\mathrm{X}$ & -- & -- & $\mathrm{X}$ & -- & -- & 2 \\
\hline Círculos & -- & $\mathrm{X}$ & -- & -- & -- & -- & $\mathrm{X}$ & 2 \\
\hline Círculos con apéndice & -- & -- & -- & -- & -- & $\mathrm{X}$ & $\mathrm{X}$ & 2 \\
\hline Círculo radiado & -- & -- & -- & -- & -- & $\mathrm{X}$ & $\mathrm{X}$ & 2 \\
\hline Círculos concéntricos & -- & $\mathrm{X}$ & -- & -- & -- & -- & -- & 1 \\
\hline Círculos contiguos & -- & -- & -- & -- & $\mathrm{X}$ & -- & $\mathrm{X}$ & 2 \\
\hline Cuadrados compuestos & -- & $\mathrm{X}$ & -- & -- & -- & -- & -- & 1 \\
\hline Manchas & $\mathrm{X}$ & -- & -- & -- & -- & $\mathrm{X}$ & $\mathrm{X}$ & 3 \\
\hline Manos en negativo & $\mathrm{X}$ & -- & -- & -- & -- & -- & -- & 1 \\
\hline Manos en positivo & $\mathrm{X}$ & -- & -- & -- & -- & -- & $\mathrm{X}$ & 2 \\
\hline Óvalos & -- & $\mathrm{X}$ & -- & -- & -- & -- & -- & 1 \\
\hline Puntiformes simples & -- & -- & $\mathrm{X}$ & -- & -- & $\mathrm{X}$ & -- & 2 \\
\hline Puntiformes compuestos & -- & -- & $\mathrm{X}$ & -- & -- & $\mathrm{X}$ & -- & 2 \\
\hline Puntos enmarcados por trazos lleno & -- & -- & -- & -- & -- & $\mathrm{X}$ & -- & 1 \\
\hline Rectángulo con diseño interno (1) & $\mathrm{X}$ & $\mathrm{X}$ & -- & -- & -- & $\mathrm{X}$ & -- & 3 \\
\hline Trazos simples & $\mathrm{X}$ & -- & -- & -- & $\mathrm{X}$ & $\mathrm{X}$ & $\mathrm{X}$ & 4 \\
\hline Trazos compuestos paralelos & $\mathrm{X}$ & $\mathrm{X}$ & -- & -- & $\mathrm{X}$ & $\mathrm{X}$ & $\mathrm{X}$ & 5 \\
\hline Trazos en cruz & $\mathrm{X}$ & -- & -- & -- & -- & $\mathrm{X}$ & $\mathrm{X}$ & 3 \\
\hline Trazos verticales paralelos enmarcados & -- & -- & -- & -- & -- & $\mathrm{X}$ & -- & 1 \\
\hline Trazos verticales paralelos... (2) & $\mathrm{X}$ & -- & -- & -- & -- & $\mathrm{X}$ & -- & 2 \\
\hline Trazos verticales paralelos cruzados... (3) & -- & $\mathrm{X}$ & -- & -- & -- & $\mathrm{X}$ & -- & 2 \\
\hline Trazos perpendiculares & -- & -- & -- & -- & -- & $\mathrm{X}$ & -- & 1 \\
\hline Trazos quebrados abiertos & -- & $\mathrm{X}$ & -- & -- & -- & & $\mathrm{X}$ & 2 \\
\hline Trazos quebrados cerrados (4) & -- & -- & -- & -- & $\mathrm{X}$ & $\mathrm{X}$ & -- & 2 \\
\hline Trazos en "U" & $\mathrm{X}$ & $\mathrm{X}$ & -- & -- & -- & $\mathrm{X}$ & -- & 3 \\
\hline Triángulos & -- & $\mathrm{X}$ & -- & -- & -- & -- & -- & 1 \\
\hline Triángulos dobles opuestos por la base & $\mathrm{X}$ & -- & -- & -- & -- & -- & -- & 1 \\
\hline Tridígitos & $\mathrm{X}$ & $\mathrm{X}$ & -- & $\mathrm{X}$ & -- & $\mathrm{X}$ & $\mathrm{X}$ & 5 \\
\hline Zoomorfos & $\mathrm{X}$ & $\mathrm{X}$ & -- & $\mathrm{X}$ & $\mathrm{X}$ & $\mathrm{X}$ & -- & 5 \\
\hline Indeterminados por morfología & -- & $\mathrm{X}$ & -- & -- & $\mathrm{X}$ & $\mathrm{X}$ & -- & 3 \\
\hline Indeterminados por conservación & -- & -- & -- & -- & -- & $\mathrm{X}$ & $\mathrm{X}$ & 2 \\
\hline Total de clases de motivos & 12 & -- & 2 & 2 & 7 & 20 & 12 & \\
\hline
\end{tabular}

Referencias: (1) Rectángulo con diseño interno = cartucho reticulado (Campan et al. 2007, tomado de Aschero y Podestá 1986); (2) Trazos verticales paralelos cruzados por otro horizontal en su parte inferior = peiniforme (sensu Aschero y Podestá 1986) o líneas paralelas pestañadas (sensu Bate 1971) y (3) Trazos verticales paralelos cruzados por otro horizontal en su parte media = hojas de palmeras (sensu Bate 1970, 1971; Molina 1972), (4) Trazos quebrados cerrados = laberintos (sensu Aschero y Podestá 1986). $f$ = de motivos compartidas entre distintos sitios.

APGA: Abrigo Pintado de Güer Aike, APMA: Abrigo Pintado de Markatch Aike, LB2: Las Buitreras 2, PAC1:Potrok Aike Cueva 1; PAA1: Potrok Aike Alero 1, ARB: Alero Romario Barría, MCh 1-8. Muralla China sitios 1-8. 
1981:197) para las que no se dispone de otras precisiones; Potrok Aike, Cueva 1 -PAC1- en donde los motivos están ubicados desde el suelo en alturas que oscilan entre 1,35 y 1,50 m y se destacan tres tridígitos negros; Potrok Aike, Alero 1 -PAA1- con pinturas dispuestas a distintas alturas llegando a alcanzar un máximo de 3m (Gómez Otero 198385) y el Alero Romario Barría -ARB- con motivos que se localizan en el sector más plano de la pared distribuidos desde el nivel del suelo actual hasta una altura máxima de $6 \mathrm{~m}$ y, se destaca la superposición de tres trazos ejecutados en negro y un tridígito de color blanco (Campan et al. 2007).

En relación al río Chico fueron identificados el Abrigo Pintado de Markatch Aike -APMA- y otras pinturas que se encontrarían muy próximas entre sí (Molina 1972). Sus localizaciones son difíciles de precisar a partir de las descripciones proporcionadas. Por esta razón, y a los fines de poder efectuar comparaciones, las distintas unidades topográficas fueron tabuladas en conjunto. Igual tratamiento debió ser otorgado a los motivos que se distribuyen sobre la extensa ladera basáltica conocida localmente como la "Muralla China" -MCh 1-8- Allí, sobre la margen derecha del río, fueron ubicados siete sitios con pinturas y sobre la margen izquierda, sólo uno. En todas esas localizaciones las manifestaciones rupestres presentan un muy mal estado de conservación (Hernández Llosas et al. 1999).

\section{EL MUESTREO DE MANIFESTACIONES RUPESTRES}

El registro de manifestaciones rupestres fue realizado en la sectores medio e inferior del río Gallegos incluyendo las mesetas basálticas de Las Buitreras y de Güer Aike. Esta distinción resulta de utilidad ante la homogeneidad geomorfológica y la amplia extensión que alcanza la formación mesetiforme que conforma la Unidad 1 del CVPA, haciendo necesario del uso de la toponimia local para definir sectores de muestreo (Carballo Marina et al. 2008). En consecuencia, el área prospectada comprende: la margen sur -sector medio- del río Gallegos, estancias Bella Vista, La Carlota y Las Buitreras y la margen norte -sector inferior-, estancia Güer Aike (Figura 2).

El relevamiento fue efectuado adhiriendo a la noción de no-sitio dentro del sitio (sensu Thomas 1975), donde cada motivo fue tratado como una unidad de ejecución independiente. Esto permite

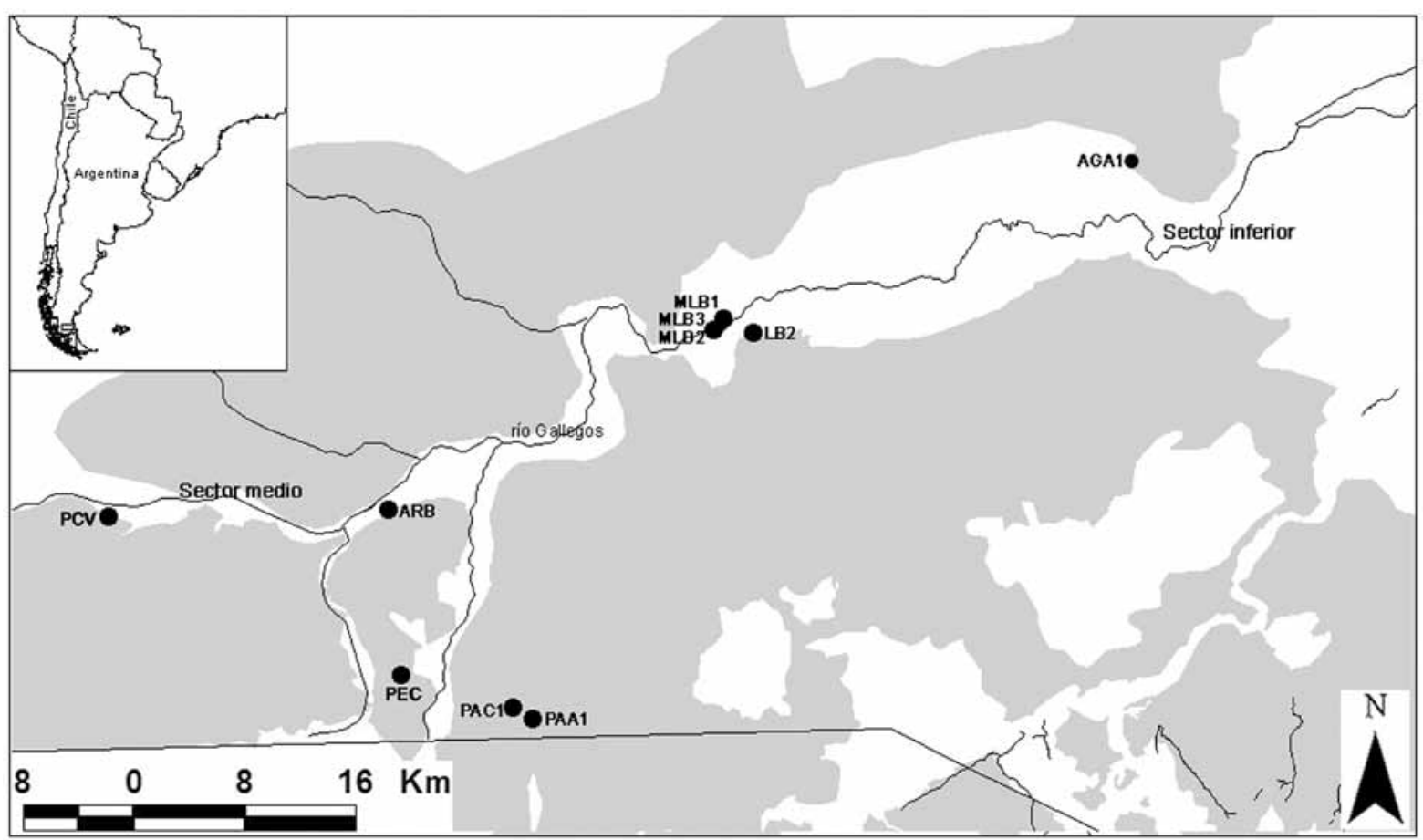

Fig. 2. Localizaciones con pinturas rupestres en los sectores medio e inferior de la cuenca del río Gallegos. 
diferenciar y contabilizar motivos simples, conformados por un único elemento, como asi también, motivos compuestos integrados por más de un elemento. A estos últimos corresponden, por ejemplo, las representaciones de tridigitos cercanos que guardan semejanzas en el diseño y en la serie tonal conformando un motivo de pisada o rastro. De modo semejante se asocian los trazos con igual orientación y dimensiones comparables que se encuentran próximos y ejecutados con igual serie tonal, siendo codificados como motivos geométricos lineales compuestos. A pesar de lo dicho, los motivos compuestos no forman escenas puesto que los diseños representados no están relacionados por vínculos anecdóticos que dan sentido a una acción y le otorgan significación metafórica al conjunto. Sino que, por el contrario, se trata de la reiteración de algún elemento. En consecuencia, el registro de pinturas rupestres estuvo dirigido a dar cuenta de las clases de soporte, la diversidad y las frecuencia de motivos, las series tonales, las técnicas de ejecución, las superposiciones y las alteraciones naturales y antrópicas que las afectan.

La asignación de los motivos rupestres al denominado "Estilo Río Chico" (Bate 1970, 1971) sólo refiere a las características lineales y geométricas que sustentan la mayoría de los diseños representados. Por lo tanto, únicamente da cuenta de las formas básicas de los motivos, cuya distribución espacial comprende a todo el CVPA, quedando explícitamente desvinculada de toda connotación étnica o cultural acerca de las poblaciones que los produjeron.

Las terminologías utilizadas en las descripciones no son mantenidas literalmente tal como fueron expresadas por los autores previos (Bate 1970, 1971; Gómez Otero 1983-85, 1988; Massone 1982; Sanguinetti de Bórmida 1981). Parte de esas tabulaciones fueron reemplazadas con el fin de ofrecer una descripción que permita unificar criterios para comparar la dispersión espacial de motivos. Fue necesario ajustarla a parámetros que dieran cuenta de las semejanzas de sus formas con figuras geométricas conocidas, evitando toda connotación que excedieran a la mera grafía del diseño (pe. trazos, círculos, etc.). Esto también significó que las variaciones observadas fueran reducidas a una misma categoría de motivos agrupando tales variantes dentro de un diseño básico considerado como la expresión más simple de su clase (pe. tridígitos, antropomorfos, zoomorfos, etc.).
La evaluación del estado de conservación de las pinturas contempló las alteraciones naturales, tales como: deterioros por roce y circulación de ganado, presencia de nidos de aves, decoloración producida por la exposición a agentes atmosféricos, acreciones y chorreaduras de precipitados químicos y desprendimientos del soporte. Mientras que, las causadas por la actividad antrópica observa el rayado de superficies y la presencia de graffiti incisos y pintados. A partir del porcentaje de motivos que tienen algún signo de alteración se calificó el estado de conservación como: excelente, cuando entre el 0 y el 25\% de los motivos están dañados, alto (26 y el 50\%), medio (51 y 75\%) y bajo (76 y 100\%).

El total de pinturas rupestres fue ejecutado con tratamiento plano haciendo uso de las series tonales: rojo bermellón, rojo carmesí, rojo escarlata, negra, blanca y ocre, de acuerdo con la tabla de valores cromáticos de Maerz y Paul (1930). Esta selección se debió al limitado número de variaciones cromáticas que utilizan esos autores, hecho que facilita la homologación con las descripciones bibliográficas, ya que en muchos casos no se cuenta con calibraciones de campo; limitando las descripciones del color a una reducida gama de variaciones, la que a su vez pueden modificarse con el tiempo como consecuencia de su oxidación, dando como resultado que las determinaciones efectuadas sobre tablas con variaciones muy acotadas puedan mostrar diferencias entre registros sucesivos.

Los soportes utilizados presentan tanto superficies planas, con cierta continuidad topográfica, como otras angulares -planos facetados-, que se extienden desde algunas decenas y hasta unos cientos de metros. Incluso, en ciertos casos se aprecia una combinación de ambos tipos.

Por otra parte, dichos soportes pueden expresarse a través de distintos rasgos del paisaje: a) paredes y paredones caracterizados por superficies continuas totalmente expuestas, b) aleros conformados por paredes enmarcadas por una visera rocosa en su parte superior y que ofrece alguna forma de reparo y c) cuevas con paredes y techos rocosos que definen un abrigo más eficiente a la intemperie. En general, todos ellos están emplazados en la base de las coladas, no obstante, unos pocos se localizan una posición intermedia, abarcando las laderas.

En la meseta basáltica de la Estancia Bella Vista las representaciones rupestres se distribuyen 
entre la base y la ladera. El sitio Puesto Cañadón Verde -PCV- se localiza a unos $560 \mathrm{~m}$ lineales al sur del río Gallegos, sobre la pared sur de un cañadón que disecta la meseta en dos segmentos. El primero, ubicado inmediatamente detrás del puesto homónimo, en una situación topográfica más baja, no registra pinturas. El segundo, localizado unos $50 \mathrm{~m}$ por encima del anterior, presenta tres paredones con manifestaciones rupestres y un motivo aislado, todos dispuestos sobre soportes naturales. En general, este frente es muy anguloso aunque ofrece algunas superficies planas con extensiones variables. Por otra parte, hay un conjunto de bloques desprendidos de la colada en los que no se registran motivos. Si bien no afectan las pinturas se observa el crecimiento de musgos y líquenes, precipitados químicos y nidos de aves.

La discontinuidad espacial existente entre sectores con pinturas permitió diferenciar: el paredón 1 -PVC 1- con una extensión de 70 m presenta un total de 86 motivos. A 260 m comienza el paredón 2 -PVC 2- con $35 \mathrm{~m}$ de largo, contabilizando 66 motivos, distante $23 \mathrm{~m}$ del paredón 3 -PCV3- que tiene 14 representaciones distribuidas a lo largo de $30 \mathrm{~m}$. El paredón 4 -PCV4- se encuentra a $10 \mathrm{~m}$ del anterior y muestra 8 motivos a lo largo de 20 $\mathrm{m}$. Finalmente, a $19 \mathrm{~m}$ se detectó un motivo aislado -PCV MA1-. Cabe señalar que, entre los sectores mencionados no se observan limitantes topográficos que permitan explicar estas discontinuidades.

Los paredones PCV1 y PCV2 son los que mayores frecuencias de motivos presentan. En cuanto a la diversidad, sin considerar los indeterminados, el PCV1 muestra 15 clases mientras que, PCV2 tiene 21 clases, a pesar de registrar una menor cantidad de representaciones. En éste último, los diseños no incluyen a todos los detectados en PCV1, ni en PCV3, pero si a los registrados en PCV4 y PCV MA1. Para facilitar la comparación regional en la Tabla 3 las clases de motivos fueron tabuladas en conjunto.

Los motivos se distribuyen entre los 0,10 $\mathrm{m} \mathrm{y}$ los 2,50 m de altura con respecto al nivel del suelo actual. Sin embargo, en la mayoría de los casos en donde la altura de las pinturas excede a las esperadas sin hacer uso de alguna clase de elevación, se observó que inmediatamente debajo de las mismas hay bloques desprendidos de la colada. Esto indica que una alta frecuencia de representaciones se distribuye dentro de lo que podría ser "el campo manual de un individuo". Por ejemplo, el motivo que se ubica a 2,50 m del nivel del talud está a 1,65 m de dos bloques caídos.

Escasas superposiciones fueron observadas. Estas se encuentran en PCV1 y se trata de un tridígito compuesto -motivo de pisadas o rastros- que se dispone por encima de un tridígito aislado y de una mancha. Mientras que, en PCV3 una mancha está superpuesta parcialmente a una serie de trazos verticales paralelos, razón por la cual sólo resultan visibles tres elementos.

El estado de conservación del conjunto pictórico es excelente. Sólo el 24\% de las representaciones muestra algún signo de alteración: en PCV1 se registraron 21 motivos desvaídos de los cuales seis fueron incluidos en la categoría indeterminados, en PCV2 se encontraron 20 alterados, cinco de ellos son irreconocibles, y en PVC3 sólo uno resulta afectado. La preservación diferencial de las pinturas no puede ser explicada por su ubicación topográfica, ni por la altura de su ejecución. Puesto que, los motivos con perturbaciones se ubican en posiciones y alturas variables en relación con el eje -horizontal- de relevamiento, no siendo posible identificar un patrón que permita atribuirlo al accionar de algún agente específico.

La totalidad de las pinturas fueron ejecutadas mediante técnica plana. No es claro si fueron realizadas utilizando los dedos o alguna clase de artefacto para su aplicación. La serie tonal rojo bermellón comprende al 99\% de los motivos registrados en PCV1, aunque se encontró un motivo de tono rojo carmesí. La situación exactamente contraria se observa en PCV2. Mientras que en PCV3, PVC4 y PVC MA1 todos los diseños fueron ejecutados en rojo bermellón.

El sitio Puesto El Cóndor -PEC- se encuentra a unos $10 \mathrm{~km}$ lineales al sur del río Gallegos y a 7,5 $\mathrm{km}$ al oeste de la laguna Potrok Aike. Se trata de un paredón localizado en un cañadón que se abre al este del valle del río Gallegos-Chico, en un sector de la ladera que muestra un desnivel topográfico abrupto. Sus paredes están colonizadas por musgos, líquenes y nidos de aves que no comprometen el estado de conservación de las pinturas rupestres (Figura 3)

Sobre un frente de aproximadamente $70 \mathrm{~m}$, distribuidas sobre soportes discontinuos, se detectaron 145 motivos ejecutados en técnica plana. En un $94,46 \%$ de ellos se empleó la serie tonal rojo 
Tabla 3. Clases y frecuencias de motivos por sitio.

\begin{tabular}{|c|c|c|c|c|c|c|c|}
\hline Clases de Motivos & PCV & PEC & MLB1 & MLB2 & MLB3 & AGA 1 & $f$ \\
\hline Antropomorfos & 3 & 0 & 0 & 0 & 0 & 0 & 3 \\
\hline Arcos & 4 & 1 & 0 & 4 & 0 & 3 & 12 \\
\hline Círculos & 4 & 0 & 0 & 0 & 4 & 0 & 8 \\
\hline Círculos con apéndice & 1 & 1 & 0 & 0 & 0 & 0 & 2 \\
\hline Círculos concéntricos & 1 & 1 & 0 & 0 & 0 & 0 & 2 \\
\hline Círculos contiguos & 3 & 2 & 0 & 0 & 0 & 0 & 5 \\
\hline Semicírculos cerrados x trazo quebrado (8) & 0 & 2 & 0 & 0 & 0 & 0 & 2 \\
\hline Cuadrados & 2 & 3 & 0 & 0 & 0 & 1 & 6 \\
\hline Cuadrados compuestos & 0 & 3 & 0 & 0 & 0 & 0 & 3 \\
\hline Cuadrados con apéndice & 0 & 2 & 0 & 0 & 0 & 0 & 2 \\
\hline Manchas & 9 & 16 & 0 & 8 & 0 & 1 & 34 \\
\hline Manos en negativo & 1 & 0 & 0 & 0 & 0 & 0 & 1 \\
\hline Manos en positivo & 0 & 1 & 0 & 0 & 0 & 0 & 1 \\
\hline Óvalos & 0 & 2 & 0 & 1 & 0 & 1 & 1 \\
\hline Óvalos con diseño interno & 0 & 1 & 0 & 0 & 0 & 0 & 1 \\
\hline Puntiformes & 5 & 3 & 6 & 5 & 0 & 2 & 21 \\
\hline Punto y trazo & 0 & 1 & 0 & 0 & 0 & 2 & 3 \\
\hline Rectángulos & 4 & 0 & 0 & 0 & 0 & 1 & 5 \\
\hline Rectángulo con diseño interno (1) & 1 & 9 & 0 & 0 & 0 & 1 & 11 \\
\hline Trazos simples & 32 & 10 & 0 & 11 & 0 & 6 & 59 \\
\hline Trazos compuestos paralelos & 61 & 38 & 1 & 24 & 1 & 6 & 131 \\
\hline Trazos en cruz & 0 & 1 & 0 & 0 & 0 & 0 & 1 \\
\hline Trazos cruzados paralelos (2) & 1 & 0 & 0 & 0 & 0 & 0 & 1 \\
\hline Trazos paralelos con uno cruzado por el medio (3) & 1 & 1 & 0 & 0 & 0 & 0 & 2 \\
\hline Trazos unidos por el centro (4) & 2 & 0 & 0 & 0 & 0 & 0 & 2 \\
\hline Trazos verticales paralelos enmarcados & 1 & 0 & 0 & 0 & 0 & 0 & 1 \\
\hline Trazos verticales paralelos cruzados... (5) & 3 & 4 & 0 & 0 & 0 & 0 & 7 \\
\hline Trazos verticales paralelos cruzados... (6) & 1 & 1 & 0 & 0 & 0 & 0 & 2 \\
\hline Trazos perpendiculares & 0 & 2 & 0 & 0 & 0 & 0 & 2 \\
\hline Trazos quebrados abiertos & 0 & 4 & 0 & 0 & 0 & 0 & 4 \\
\hline Trazos quebrados cerrados (7) & 1 & 0 & 0 & 0 & 0 & 1 & 1 \\
\hline Trazos en "U" & 5 & 2 & 0 & 0 & 0 & 0 & 7 \\
\hline Trazos en "V" & 4 & 2 & 0 & 0 & 0 & 0 & 7 \\
\hline Triángulo con apéndice & 0 & 1 & 0 & 0 & 0 & 0 & 1 \\
\hline Tridígitos & 8 & 13 & 0 & 0 & 0 & 2 & 23 \\
\hline Zoomorfos & 0 & 1 & 0 & 0 & 0 & 0 & 1 \\
\hline Indeterminados por morfología & 5 & 9 & 0 & 3 & 0 & 1 & 18 \\
\hline Indeterminados por conservación & 12 & 8 & 0 & 4 & 0 & 0 & 24 \\
\hline Totales & 175 & 145 & 7 & 60 & 5 & 28 & \\
\hline
\end{tabular}

Referencias: (1) Rectángulo con diseño interno = cartucho reticulado (tomado de Aschero y Podestá 1986, Campan et al. 2007,); (2) Trazos cruzados paralelos = numeral; (3) Trazos paralelos con uno cruzado por el medio = $\mathrm{H}$ del alfabeto latino; (4) Trazos unidos por el centro = asterisco; (5) Trazos verticales paralelos cruzados por otro horizontal en su parte inferior = peiniforme (sensu Aschero y Podestá 1986) o líneas paralelas pestañadas (sensu Bate 1971), (6) Trazos verticales paralelos cruzados por otro horizontal en su parte media = hojas de palmeras (sensu Bate 1970, 1971; Molina 1972), (7) Trazos quebrados cerrados = laberintos (sensu Aschero y Podestá 1986), (8) Semicírculos cerrados por trazo quebrado = campaniforme. PCV: Puesto Cañadón Verde, PEC: Puesto El Cóndor; MLB1: Meseta Las Buitreras 1, , MLB2:

Meseta Las Buitreras 2, MLB3: Meseta Las Buitreras 3, AGA1: Abrigo de Güer Aike 1.

bermellón (137), en el 4,17\% la rojo carmesí (6) $y$ en el $1,37 \%$ se utilizaron ambas series tonales conformando dos bicromías.

Se registraron dos motivos reciclados. Uno corresponde a trazos paralelos con otro cruzado por el medio - $\mathrm{H}-$, donde por la prolongación de uno de ellos fue convertido en "hoja de palmera" (trazos verticales paralelos cruzados por otro horizontal en su parte media, Figura 4) y el otro a un tridígito devenido en zoomorfo (Figura 5). Un tercer caso podría estar dado por la conformación de un "peiniforme" (trazos verticales paralelos cruzados por otro horizontal en su 


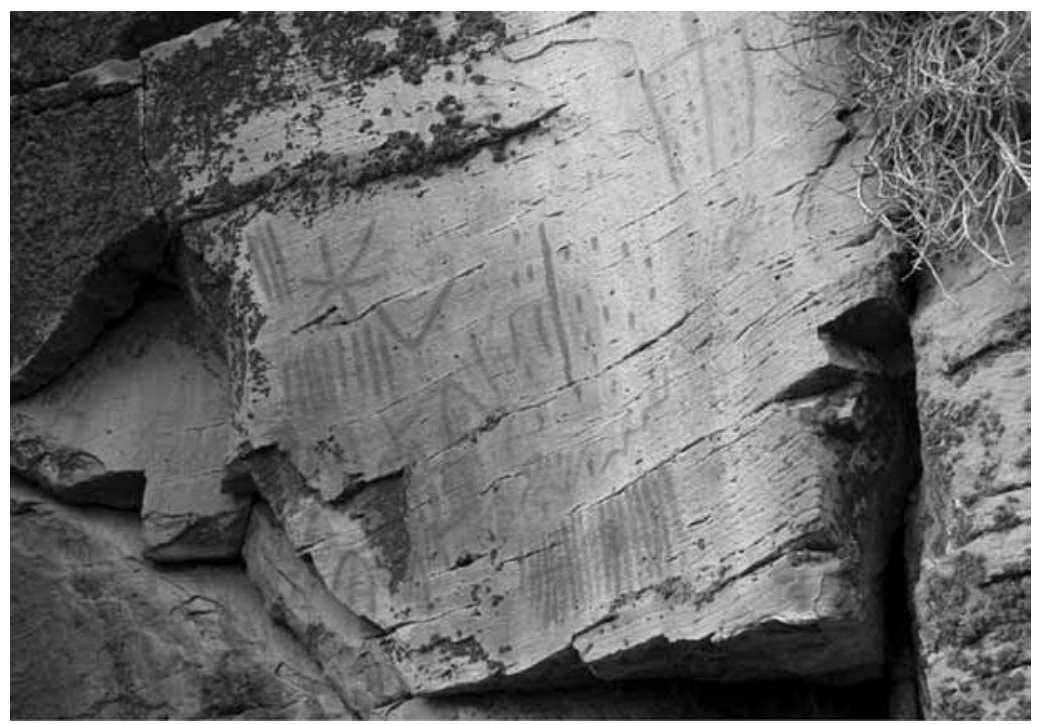

Fig. 3. Puesto el Cóndor. Detalle pared.

parte inferior) logrado mediante el pintado de trazos verticales paralelos cortos y un trazo curvo que -desde abajo y de izquierda a derecha- lo enmarca parcialmente. Asimismo, se constataron nueve superposiciones entre las que se destaca un diseño de trazos paralelos compuestos que se encuentra por encima de una mancha roja y, por debajo de un tridígito.

El estado de conservación de las pinturas es excelente, sólo el 24,13\% de los motivos exhibe algún tipo de alteración. Se notaron 27 motivos desvaídos de los cuales ocho no pueden ser reconocidos por sus diseños, otros dos están afectados por musgos y cinco muestran brillos en su superficie. Cuatro de ellos se ubican por encima de los 0,70 m, por lo que la alteración observada se la atribuye a pátina.

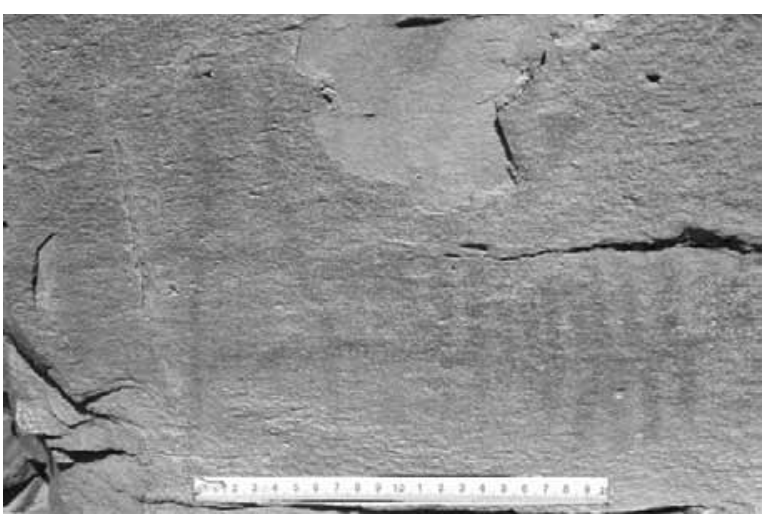

Fig. 4. Puesto El Cóndor. Motivo reciclado -trazos paralelos con uno cruzado por el medio $(\mathrm{H})$ donde la prolongación de uno de los trazos fue convertido en "hoja de palmera".
Mientras que un tercero -ubicado a $0,45 \mathrm{~m}$ del sueloes posible que esté engrasado por el frotamiento de ovinos. Un pequeño sector del paredón demuestra indicios de meteorización, donde el desprendimiento de un fragmento del soporte arrastró parte de un motivo geométrico complejo. Resta mencionar que en la pared de la colada pero, sin afectar de modo directo a las representaciones rupestres, se registra un graffiti subactual.

En la pared noroeste de esta misma colada, a unos $6 \mathrm{~km}$ al oeste del sitio PEC, bordeando una cuenca endorreica de grandes dimensiones, denominada localmente Bajo El Cóndor -o Bella Vista- se encuentra una cueva de reducidas dimensiones con una baja frecuencia de pinturas (Carballo Marina et

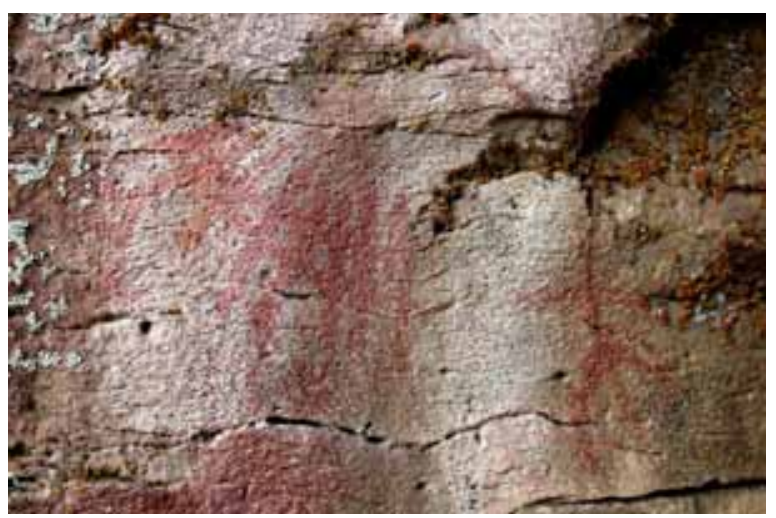

Fig. 5. Puesto El Cóndor. Tridígito reciclado en zoomorfo. 


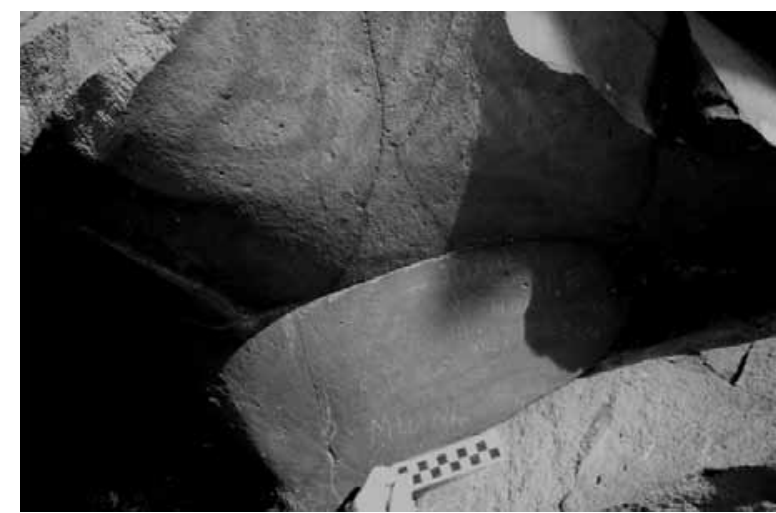

Fig. 6. Meseta Las Buitreras 2. Caso de superposiciones en igual situación topográfica con evidencia de vandalismo.

al. 2008). Este reparo se ubica en la base de la colada que está emplazada ca. $100 \mathrm{~m}$ del nivel del suelo y que expone una extensa ladera sobre la que se depositaron bloques de basalto y sedimentos eólicos.

En Estancia Las Buitreras se identificaron varios reparos rocosos de pequeñas dimensiones, sólo en algunos se registraron manifestaciones rupestres. El sitio Meseta Las Buitreras 1 -MLB1- es un abrigo que tiene $1,40 \mathrm{~m}$ de ancho por 4,00 $\mathrm{m}$ de profundidad y 2,10 m de alto. En el lado externo de la boca se identificaron siete motivos abstractos en la serie tonal rojo bermellón. Los soportes utilizados se presentan de manera discontinua. El estado de conservación de las pinturas es excelente, puesto que no se detectó ningún motivo alterado.

El Abrigo Pintado de Las Buitreras -APLBfue solamente mencionado por Molina (1972), por lo que se procedió a su relevamiento, siendo redenominado Meseta Las Buitreras 2 -MLB2-. Es un alero de $4 \mathrm{~m}$ de ancho por 4,50 $\mathrm{m}$ de profundidad y $2,50 \mathrm{~m}$ de alto. Registra un total de 60 motivos ejecutados en varios de los planos que muestra el soporte. Resulta llamativa la alta superposición de elementos que presenta un bloque caído, para el que no es posible reconocer si su ubicación actual se debe a un desprendimiento ocurrido una vez que se encontraba pintado o si, por el contrario, las pinturas fueron ejecutadas posteriormente (Figura 6). La ausencia de negativos reconocibles en las paredes del alero permite pensar que ese bloque se habría desprendido sin pintar junto con otros, impidiendo así remontar su lugar de procedencia original. Lo expuesto induce a pensar que podría haber sido pintado en su posición actual. Apoyan esta propuesta el hecho que una de sus caras laterales también está pintada y uno de esos motivos ocupa parte del frente, sumado a que las representaciones no tienen evidencia de estar fragmentadas. Por otra parte, se observan superposiciones parciales entre pinturas que se encontraban desvaídas. Esto podría indicar por un lado, la reutilización de ese soporte $y$, por otro, que bajo condiciones semejantes de exposición, los episodios de producción pictórica podrían estar separados por lapsos prolongados.

Las pinturas fueron ejecutadas mediante técnica plana en la serie tonal rojo bermellón. El estado de preservación es excelente, dado que sólo el 15\% de los motivos tienen evidencias de alteración, y tres clasificados como indeterminados por conservación. Asimismo, se registran otros motivos con perturbaciones, no obstante ello, sus diseños resultan reconocibles: cuatro están desvaídos y dos fragmentados a causa del desprendimiento de una porción del soporte.

En la cueva MLB3, cuyas dimensiones alcanzan los $5 \mathrm{~m}$ de ancho por $4 \mathrm{~m}$ de profundidad y 2,50 $\mathrm{m}$ de alto, se registraron cinco motivos ubicados en el techo del abrigo sobre un soporte discontinuo. La técnica de ejecución es plana y la serie tonal rojo bermellón. El estado general de conservación de las pinturas es excelente dado que no registran alteraciones. Sin embargo, en distintos sectores del soporte sin manifestaciones rupestres se reconocieron nombres y fechas pintadas o grabadas. Además de la presencia de nidos abandonados y concreciones de carbonato de calcio que tampoco afectan a las representaciones.

En la margen norte del río Gallegos se localizó el sitio Alero 1 de Güer Aike -AGA1-. Este abrigo de 3,90 $\mathrm{m}$ de ancho por 3,90 $\mathrm{m}$ de profundidad y $4 \mathrm{~m}$ de alto posee un total de 28 motivos ejecutados sobre distintos planos de la pared. Sólo dos corresponden a la serie tonal rojo carmesí mientras que el resto a la serie tonal rojo bermellón. El estado de conservación de las pinturas es medio, el 71,42\% se encuentra muy perturbado por vandalismo. Hay motivos afectados por rayados incisos, el grabado de números y nombres, tizados y pintados con esmalte sintético blanco.

La información consignada en la Tabla 3 permite concluir que, sin considerar los motivos indeterminados, en el sitio PCV hay 26 clases de motivos representadas, en PEC ascienden a 30, en AGA1 a 13, en MLB2 (APLB) a ocho y en MLB1 y MLB3 
son dos. Esto indica que no hay una relación entre la diversidad de motivos y la extensión de los soportes.

Los diseños comunes a todas las localizaciones son los trazos compuestos paralelos, seguidos por los puntiformes. El tercer lugar es compartido por los arcos, las manchas y los trazos simples. Por otra parte, se han detectado diseños que son exclusivos de un sitio en particular. Siete motivos corresponden al sitio PCV, incluyendo antropomorfos, círculos, negativos de manos, rectángulos, trazos cruzados paralelos, trazos unidos por el centro, trazos verticales paralelos enmarcados y trazos quebrados cerrados. Mientras que, en PEC se observaron 11 diseños que le son propios: semicírculos cerrados por trazo quebrado, cuadrados con apéndice, positivo de manos, óvalos, óvalos con diseño interno, punto y trazo, trazos en cruz, trazos perpendiculares, trazos quebrados abiertos, triángulo con apéndice y zoomorfos. Lo señalado indica que no sólo la diversidad de diseños es elevada, si no que también se distribuyen de modo diferente en el espacio.

El concepto básico que engloba a la mayoría de los motivos abstractos se circunscribe a un limitado número de elementos geométricos, tales como: puntos, trazos, arcos y círculos que se combinan de modos diferentes aumentando la variedad de motivos. Mientras que, los motivos figurativos engloban menos cantidad de diseños, que por encontrarse mayormente definidos toleran menos variabilidad. Entre estos se encuentran zoomorfos, antropomorfos, tridígitos y manos.

La distribución de manifestaciones rupestres evidencia que en todos los casos fueron utilizados soportes naturales cercanos a la base de la colada -posición inferior-. Algunas diferencias residen en la clase de exposición que presentan, si se trata de localizaciones abiertas y expuestas, como ser paredes y paredones, o protegidas y/o delimitados topográficamente, como son cuevas y aleros.

Lo expuesto no permite sostener que la oferta de superficies naturalmente aptas para la producción pictórica fue condición suficiente para el registro de pinturas. Razón por la cual, y tomando en cuenta la alta frecuencia de reparos potenciales que se observan en los tramos medios e inferior del río Gallegos, en la elección y conformación de los espacios plásticos de representación debieron haber intervenido otros criterios, además de la disponibilidad de soportes.

Un análisis más detallado de los soportes indica que los motivos se distribuyen, básicamente, de manera discontinua a lo largo de la colada (Tabla 4). En el caso de los paredones, la discontinuidad pictórica queda establecida en las distancias que los separa a pesar de que pueden no existir limitantes topográficos. En el caso de los aleros y de las cuevas esa discontinuidad se asocia a la conformación de reparos en la meseta basáltica.

Al comparar las frecuencias de clases de motivos entre localizaciones se ve que los diseños abstractos son los más recurrentes (Tabla 4). En esta oportunidad, los motivos indeterminados por morfología fueron incluidos dentro de los abstractos, reservando la categoría indeterminados para aquellos motivos que resultan irreconocibles a causa de su deterioro. Los trazos compuestos son los más abundantes, seguidos por los trazos simples y las manchas. En tanto que los motivos figurativos presentan frecuencias comparativamente muy bajas y circunscriptas a negativos y positivos de manos, tridígitos, zoomorfos y antropomorfos (Tabla 3).

La serie tonal rojo bermellón es la más utilizada en la ejecución de motivos y está presente en todas

Tabla 4. Localizaciones y frecuencias de motivos.

\begin{tabular}{|c|c|c|c|c|c|c|c|c|c|c|c|}
\hline \multirow{2}{*}{ Sitios } & \multirow{2}{*}{ Reparos } & \multirow{2}{*}{$\begin{array}{l}\text { Dimensiones } \\
\mathrm{A} \times \mathrm{Z} \times \mathrm{h} \mathrm{m}\end{array}$} & \multirow{2}{*}{ Soportes } & \multicolumn{3}{|c|}{ Motivos } & \multicolumn{5}{|c|}{ Series tonales } \\
\hline & & & & $\mathrm{Ab}$. & Fig. & Ind. & B & $\mathrm{N}$ & $\mathrm{RB}$ & $\mathrm{RC}$ & $\mathrm{Bi}$ \\
\hline ARB & alero & $30 \times 4 \times 6$ & continuo & 107 & 6 & 25 & 1 & 3 & 134 & 0 & 0 \\
\hline PCV & paredón & $450 \times 5 \times 2,50$ & discontinuo & 151 & 12 & 12 & 0 & 0 & 108 & 66 & 1 \\
\hline PEC & paredón & $70 \times 5 \times 2,50$ & discontinuo & 122 & 15 & 8 & 0 & 0 & 134 & 7 & 2 \\
\hline MLB1 & cueva & $1,40 \times 4 \times 2,10$ & discontinuo & 7 & 0 & 0 & 0 & 0 & 7 & 0 & 0 \\
\hline MLB2 & alero & $4 \times 4,50 \times 2,50$ & discontinuo & 56 & 0 & 4 & 0 & 0 & 60 & 0 & 0 \\
\hline MLB3 & cueva & $5 \times 4 \times 2,50$ & discontinuo & 5 & 0 & 0 & 0 & 0 & 5 & 0 & 0 \\
\hline AGA1 & alero & $3,90 \times 3,90 \times 4$ & discontinuo & 26 & 2 & 0 & 0 & 0 & 26 & 2 & 0 \\
\hline
\end{tabular}

Referencias: $\mathrm{Ab} .=$ Abstractos, Fig. $=$ Figurativos, Ind. = Indeterminados, $\mathrm{B}=$ blanca, $\mathrm{N}=$ negra, $\mathrm{RB}=$ rojo bermellón, $\mathrm{RC}=$ rojo carmín, $\mathrm{Bi}=$ bicromías $(\mathrm{RB}$ y $\mathrm{RC}$ )

ARB: Alero Romario Barría, PCV: Puesto Cañadón Verde, PEC: Puesto El Cóndor; MLB1: Meseta Las Buitreras 1, MLB2: Meseta Las Buitreras 2, MLB3: Meseta Las Buitreras 3, AGA1: Abrigo de Güer Aike 1. 
las localizaciones. En menor frecuencia se ubica la serie tonal rojo carmesí detectada en pocos motivos $y$ ausente en varios sitios. Sin embargo, a pesar de su baja representatividad conforma bicromías junto con el otro tono de rojo.

Es interesante señalar que, en PCV 1 donde los motivos responden casi exclusivamente a la serie tonal rojo bermellón se encuentra un único motivo en rojo carmesí y en PCV2 el caso es exactamente inverso. Esto podría estar indicando posibilidades contrapuestas: a) cierta simultaneidad en la producción de pinturas o bien, b) planificación en la utilización de soportes ya sea en la creación del espacio plástico de representación a partir de la alternancia pictórica de un único motivo en cada pared o, de eventos de producción mediatizados en el tiempo. Se constata también la reutilización de esos mismos espacios a través de las superposiciones y de los reciclados de motivos ejecutados en idéntica serie tonal -bermellón-. Aún resta dilucidar si las bicromías corresponden a un mismo momento de ejecución o se trata de una sumatoria de trazos dentro de una secuencia de trazos compuestos preexistente.

\section{TENDENCIAS EN LA DIVERSIDAD DE MOTIVOS}

En el sector chileno se identificaron 29 sitios con pinturas rupestres, pero como fuera expuesto precedentemente, se desconoce la extensión de los soportes y las frecuencias de motivos en muchas de ellas, razón por la cual, no es posible establecer otras comparaciones que las sustentadas en el ranking de diversidad y de la presencia/ausencia de motivos.

En la Tabla 1, puede consultarse la diversidad de diseños existentes. El total de clases reconocidas asciende a 31, siendo su expresión distribuidas de mayor / menor por sitios la siguiente: CL (15), LSo1 (13), CB5 (10), UA-RC5-CS2 (8), RC1 (7), MC-RC2-LS1-LS2(6), LT2-RA3-LLT1-JA4-CB2 (5), RGC-LS3 (4), RC0-CS1-CB3-CB4 (3), CS4-LS4 (2) y F-L1-LT3-CB1 (1).

Las localizaciones que comparten alguna clase de motivos son 22, excluyendo en este conteo a los indeterminados por conservación. El diseño más representado son los trazos compuestos paralelos presentes en 21 sitios, seguido por las manchas en 14, los trazos simples en 12 , los puntiformes compuestos en $11 \mathrm{y}$ los puntiformes simples en ocho. Estas grafías pueden considerarse básicas ya que pueden usarse como elementos constitutivos de otros diseños un poco más complejos.

Los sitios que exhiben motivos propios son nueve, entre estos se encuentran: negativos de manos (RC5), positivos de manos (RA3), círculos concéntricos (RC1), cuadrados con apéndices (CB5), espirales con trazo punteado (CB5), semicírculos cerrados por trazo quebrado (RC0), trazos verticales paralelos cruzados por otro horizontal en su parte media -hojas de palmera- (UA), trazos verticales intercalados por una hilera de puntos (RC5) y trazos perpendiculares -tipo numeral- (CL). Al comparar estas clases de diseños con las mencionadas en el párrafo anterior se observa que pictográficamente son más complejos pudiendo ser resultado de una combinación de elementos, o representar formas geométricamente más definidas, semejantes a polígonos o figuras geométricas. Al mismo tiempo, resulta importante destacar que a pesar de registrarse clases de motivos exclusivas a ciertos sitios, estas no se correlacionan con una mayor diversidad de diseños existente en los mismos. Por lo cual no puede esperarse que una mayor frecuencia de motivos conlleve también a una mayor diversidad de clases. Esto significa que por más que se amplíe la muestra, no necesariamente aumentará la variabilidad de clases reconocidas, dando como resultado que la representación de diseños pocos frecuentes exprese selecciones específicas dentro de un repertorio de formas posibles.

En el sector argentino del CVPA son 13 los sitios en donde se registraron motivos rupestres (Tablas 2 y 3). Las clases de diseños indentificadas ascienden a 41 , sin contabilizar los indeterminados por conservación. Los sitios ordenados de mayor a menor diversidad de clases son: PEC (30), PCV (26), ARB (20), APMA (14), AGA1 (13), APGA y MCh1-8 (12), APLB (8), PAA1 (7) y LB2-PAC1-MLB1-MLB3 (2). Al comparar la diversidad de diseños por sitios se observa que en este conjunto de datos sí hay una correlación positiva entre variabilidad y abundancia de motivos.

Entre los motivos que son exclusivos a ciertas localizaciones se encuentran: semicírculos cerrados por trazo quebrado -campaniforme- (PEC), cuadrados con apéndices (PEC), óvalos con diseño interno (PEC), puntos enmarcados por trazo lleno (ARB), trazos cruzados paralelos -tipo numeral- (PCV), trazos unidos por el centro -símil asterisco- (PCV), triángulo 
(APMA), triángulo con apéndice (PEC) y triángulos dobles opuestos por la base (AGPA). Se trata una vez más de diseños geométricos más complejos que combinan elementos simples tales como puntos y trazos. Al mismo tiempo se registran figuras geométricas con el agregado de elementos simples -diseños interiores y apéndices-. La exclusividad de ciertos diseños en el sector norte del CVPA también parece tener correlación positiva con la mayor diversidad de motivos presentes en las distintas localizaciones.

En ambos sectores del CVPA las pinturas fueron ejecutadas con tratamiento plano. Las comparaciones (Tablas 1,2 y 3) muestran que en el sector chileno la diversidad de motivos (31) es menor, a pesar de que es mayor el número de sitios descriptos (29). Por su parte, el sector argentino expone una mayor variabilidad de motivos (41) en una muestra menor de sitios (13). Estas diferencias permiten sostener que, más allá de los distintos tamaños de las muestras, los conjuntos expresan la variabilidad existente en este tipo de registro arqueológico y, lo convierten en una vía de constrastación válida e independiente para evaluar procesos de ocupación del espacio.

Ninguna clase de motivo está presente en todos los sitios, los trazos compuestos paralelos (32) seguidos por las manchas (21) y los trazos simples (20) son los que más recurrentes en las distintas localizaciones. Los motivos más frecuentes en el sector sur del CVPA corresponden a diseños abstractos -trazos compuestos paralelos, manchas, trazos simples y puntiformes compuestos-. En tanto que en el sector norte a los motivos de trazos -abstractos- le siguen los tridígitos -figurativos-, luego las manchas -abstractos- y los zoomorfos -figurativos-. Si bien las diferencias observadas son débiles deben ser consideradas puesto que aluden a una tendencia representativa de carácter más figurativo, que se expresa en un sentido zoomórfico (tridígitos y zoomorfos) y antropomórfico (negativos y positivos de manos y antropomorfos).

Las clases de motivos que están ausentes en el sector sur son: círculos con apéndice, cuadrados, puntos enmarcados por trazo lleno, puntos y trazos, rectángulos, trazos en cruz, trazos cruzados, trazos verticales paralelos cruzado por uno horizontal, trazos unidos por el centro, trazos verticales paralelos enmarcados, trazos quebrados cerrados, triángulos y triángulos dobles opuestos por la base. Por su parte, en el sector norte no se registran: espirales trazo punteado y trazos verticales intercalados por hileras de puntos, quizás estas "ausencias" junto con la menor cantidad de clases en este último sector, también puedan ser explicada en términos poblacionales y de circulación de ideas, tal vez facilitada por la cercanía a espacios de uso diferencialmente más intensivos -tales como la costa, espacios abiertos o mallines con alta concentración de biomasa- o a nodos de circulación -cuerpos de aguas permanentes- (Borrero y Manzi 2007). Donde la circulación oeste-este y viceversa podría estar encauzada a través de sectores de menor fricción al transito como serían las planicies de inundación de los ríos. Mientras que la direccionada norte-sur y recíprocamente, podría encontrarse en relación con la costa -atlántica y del estrecho de Magallanes-.

Al integrar ambas regiones en una escala suprarregional, apuntalando la idea de circulación humana en relación al CVPA, se observa que ciertas clases de motivos que eran exclusivos de uno de esos sectores dejan de serlo y pasan a ser compartidos con otras localizaciones distantes. Tal es el caso de los cuadrados con apéndices registrados en CB5 y PEC y de los triángulos con apéndices presentes en PEC, CL y UA.

La mayor parte de los motivos fueron ejecutados en series tonales rojas. No obstante, para pintar algunas clases se utilizaron otros tonos. En negro se registra un antropomorfo (CL), positivos de manos (APGA), tridígitos (CL-PAC1), un trazo simple (CB5) y trazos compuestos (ARB). En blanco un antropomorfo (UA), un negativo de manos (RC5), un círculo concéntrico (RC1), un motivo indeterminado por morfología (CL) y un tridígito (ARB). También se reconocen algunas bicromías utilizando distintas series de rojos (bermellón y carmesí) en dos motivos en "U" (PCV), tridígitos y trazos compuestos (PEC); series roja y negra no especificándose a qué clase de diseño corresponde (CL), arcos (UA-CS2) y un puntiforme (RC2). Las series roja y ocre se emplearon para plasmar un indeterminado por morfología (LSo1). En general, las series tonales negras y blancas como las bicromías son utilizadas para pintar motivos poco frecuentes en el CVPA. Algunos de las cuales tienen una distribución espacial que lo excede, tal es el caso de los tridígitos, los antropomorfos y los negativos y positivos de manos registrados por ejemplo, en la meseta central santacruceña (Carden 2008 y bibliografía allí citada). 
Las representaciones se distribuyen entre unos pocos centímetros del nivel del piso actual, llegando como máximo a 3 m (LT2-PAA1). Un caso extremo esta dado por un motivo que se ubica a 6 $m$ de altura (ARB), cuando la cota media oscila en torno al 1,60 m, lo cual permite pensar en que la ejecución de pintura se realizaba dentro de lo que podría ser identificado como el campo manual de un individuo. Tal como se mencionara, en el sitio PCV se registró un motivo ubicado a una altura que lo excede ampliamente. Sin embargo, la presencia de bloques depositados justamente debajo de ese motivo permite proponer que pudieron haber sido utilizados como un medio de elevación.

Se constataron pocas superposiciones de motivos. Si bien es cierto que esta clase de relaciones son significativas al momento de obtener cronologías relativas, aquí resultan de interés para reconocer qué clases de motivos intervienen dando idea de redundancia ocupacional. Las superposiciones detectadas comprenden: en PEC, mancha/rectángulo/ tridígito; trazos quebrados abiertos/trazos verticales compuestos; rectángulo/tridígitos, rectángulo con diseño interno/ovalo y diseños indeterminados por conservación/puntiforme; en PCV, tridígitos/mancha, tridígitos/tridígito y en $\mathrm{ARB}$, motivo indeterminado por morfología/dos motivos de trazos verticales paralelos cruzados por otro horizontal en su parte media -hojas de palmeras-, trazos compuestos/ trazos compuestos, puntiforme/indeterminado por conservación y tridígitos/trazos compuestos.

Además, se reconocieron casos de reciclados de motivos comprendidos por un rectángulo con diseño interno y trazos compuestos convertidos en trazos verticales paralelos cruzados por otro horizontal en su parte media -hojas de palmeras- (PEC) y un tridígito en zoomorfo -matuasto-. A pesar de que no se observa un patrón de superposiciones definido, es posible mencionar que las clases de motivos que intervienen corresponden a aquellas de representación más frecuente. En contraposición, los diseños menos frecuentes parecen ser los que se mantienen sin modificaciones intencionales visibles.

Por último, resta señalar que hay diseños sobre soportes móviles que son comparables a los registrados en los reparos rocosos vinculados con contextos de inhumación. Este es el caso del colgante proveniente de Morro Chico -MC- (Prieto 1984) además, de un instrumento con decoración incisa realizado sobre un metatarso de guanaco y dos punzones de huesos de aves, también con decoración incisa, uno de ellos paralela y oblicua con restos de ocre en su interior y el otro con incisiones paralelas y borde denticulado recuperados en el sitio Orejas de Burro 1 (L'Hereaux 2008).

\section{DISCUSIÓN Y CONCLUSIONES}

Los soportes que conforman los distintos espacios plásticos de representación muestran algunas diferencias en relación con los distintos sectores del CVPA. En la cuenca del río Chico y en la región de Última Esperanza los motivos estarían ejecutados en aquellos lugares de las coladas basálticas que presentan superficies aptas para la producción de pinturas (Bate 1971; Hernández Llosas et al. 1999; Gallardo 2009), lo cual parecería indicar una disponibilidad limitada de este recurso. Una situación semejante se produciría en relación con la laguna Potrok Aike, sitios PAC1 y PAA1 (Gómez Otero 1983-85, 1989-90). En estos casos, se puede aceptar que existe algún grado de condicionamiento en la distribución de localizaciones con manifestaciones rupestres infligido por la disponibilidad de soportes.

En cambio, en los relevamientos realizados en los sectores medio e inferior del río Gallegos -a pesar de que algunas localizaciones muestran mayores frecuencias de motivos que otras- no parecen indicar una relación directa con la disponibilidad de soportes, si no con elecciones humanas. Lo dicho se observa en el sitio ARB, donde se concentra una alta frecuencia de motivos en un sector restringido de la pared desestimando otras superficies planas con condiciones, al parecer, igualmente óptimas. En el sitio PCV se evidencia discontinuidad en la distribución de motivos, alternando espacios pintados con otros sin pintar que presentarían condiciones similares. Esta situación pone de manifiesto la elección de ciertos sectores por sobre otros. A la vez, se aprecia que en MLB1, MLB2 y MLB3 los escasos diseños existentes contrastan con las abundantes superficies pasibles de ser utilizadas. En el AGA1 los motivos están restringidos a un alero con poco reparo efectivo, descartando otras superficies muy próximas con un potencial semejante para la producción pictográfica.

En MLB2 se evidencia un caso de reutilización de un mismo lugar de la colada para la ejecución de pinturas. En este espacio se encuentra un bloque con 
motivos superpuestos realizados en la misma serie tonal -rojo bermellón-, los ubicados por debajo están muy desvaídos, mientras que, los se disponen por encima no lo están. Dadas las mismas condiciones de exposición el mayor deterioro de una de las series pictóricas se explicaría por la distancia cronológica entre esos episodios de producción. Lo expuesto, sumado a la alta disponibilidad de soportes permite pensar que no es la abundancia/escasez de superficies el principal criterio que interviene en la elección de lugares, como tampoco lo habría sido la extensión de las paredes rocosas.

En consecuencia se puede concluir que, en la cuenca del río Gallegos la localización de manifestaciones rupestres está menos circunscripta -o condicionada- por la disponibilidad de soportes. Situación que sí se ajustaría a los sitios con pinturas reconocidos en relación con el río Chico.

La resolución cronológica de los contextos analizados es muy escasa. El estudio de superposiciones de motivos podría ser una vía de entrada para la separación de eventos de producción de pinturas. En los sitios analizados no resulta posible precisar las distancias temporales que guardan estos eventos entre sí, dada la poca diferenciación existente entre los diseños y las series tonales junto con las bajas frecuencias de motivos superpuestos. No obstante, la superposición y el reciclado de motivos indica procesos acrecivos (Stern 1994) que podrían atribuirse a redundancia ocupacional. Por otra parte, la alternancia de motivos con series tonales distintas en los paredones 1 y 2 del sitio PCV permite suponer que en algunos casos la producción de pinturas podría estar asociada a la presencia de motivos preexistentes. Mientras que, los motivos aislados podrían dar cuenta de alguna planificación en la conformación de los espacios plásticos de representación funcionando como marcas hechas en lugares seleccionados y, actuarían como atractores para futuras ejecuciones.

No se conoce aún la composición mineralógica de los pigmentos con que fueron producidas las pinturas como tampoco se identificaron sus posibles fuentes en el área prospectada por este equipo de investigación. En cambio, sí fueron detectados lugares potenciales de aprovisionamiento de pigmentos -posiblemente hematita-, en distintos sectores de las coladas basálticas que enmarcan el curso del río Chico (sensu Hernández Llosas et al. 1999; San Román et al 2000). Lo señalado, indicaría una dis- ponibilidad heterogénea de este recurso que podría obtenerse tanto localmente como dentro de circuitos de movilidad más amplios; los que además de incluir sustancias inorgánicas habrían involucrando otras de origen orgánico como las utilizadas para lograr tonos blancos y negros (Sepúlveda 2011).

La imposibilidad de disponer de las frecuencias de motivos para cada uno de los sitios determinó que las comparaciones se efectúen entre clases de motivos descriptas en términos de su semejanza con figuras geométricas básicas -puntos, líneas y polígonos- y una cantidad limitada de combinaciones que aumentan la diversidad de diseños representados. A estas formas básicas se suman unos pocos motivos figurativos relacionados con representaciones zoomórficas (zoomorfos y tridígitos) y antromórficas (manos, antropomorfos y arrastres de dedos).

En el sector sur del CVPA los diseños más frecuentes son los abstractos -trazos compuestos paralelos, manchas, trazos simples y puntiformes compuestos-. Por su parte, en el norte a los motivos de trazos -abstractos- le siguen los tridígitos -figurativo-, luego las manchas y los zoomorfos. Las diferencias entre ambos sectores son débiles y se expresan en la representación de motivos figurativos en el último de ellos. No obstante, se podría pensar que los trazos y las manchas podrían funcionar de modo semejante a las marcas o índices dejadas al apoyar, arrastrar o frotar distintas partes del cuerpo humano sobre una variedad de superficies -no necesariamente para la producción de pinturas-, funcionando a la manera de signos visuales secundarios inanimados (sensu Mithen 1996). Estos diseños podrían estar inspirados en y por rastros animales, tal como los tridígitos. En ese caso, las manchas resultarían comparables a improntas pudiendo ser los motivos de manos una posible variante iconográfica -figurativa-, cuya representación sería más precisa y más rígidamente definida En cambio, los trazos serían un equivalente de rastros humanos tales como arrastres de dedos como se constata en MLB2.

Los diseños abstractos presentan una estructura de composición semejante, se desarrollan a partir de puntos, líneas y polilíneas -tales como arcos, círculos, rectángulos y cuadrados-. Estas clases de diseños, que puede ser pensadas como simples, son susceptibles de ser explicadas tomando en consideración formas de transmisión cultural débiles, las que dejarían margen y, a la vez, tolerarían ciertas variaciones en las estructuras de los diseños 
(Shennan 2000). Estructuras gráficas que permiten variaciones en su morfología serían las esparadas en lugares en donde la presencia humana es efímera. La falta de una prolongada interacción humana impide que las formas de transmisión sean más supervisadas. En este sentido, los motivos abstractos pueden funcionar como indicadores de sectores de circulación en espacios con escasa fricción al tránsito y, con poblaciones humanas dispersas en espacios muy grandes donde las intensidades de las ocupaciones son bajas a pesar del alto potencial de visita a esos lugares.

Las bajas frecuencias en la representación de motivos figurativos -antropomorfos, zoomorfos, tridígitos y manos en positivo y negativo- quizás puedan explicarse en formas de transmisión cultural más rígidas o tal vez más pautadas (Shennan 2000). $\mathrm{Su}$ ejecución habría requerido de procedimientos más costosos, al tolerar una menor variabilidad en los diseños, por lo que su copia debería ser más cuidada motivando a que, tal vez, adquirieran una significación diferente dentro de los sistemas de circulación de información.

La distribución de las clases de motivos resiste dos líneas explicativas. Una que enfatiza la presencia de diseños compartidos por distintas localizaciones y otra que destaca la ausencia de ciertas clases. Al ampliar los muestreos en el sector argentino del CVPA se evidencia que algunas clases que parecían exclusivas del sector chileno dejan de serlo. Asimismo, fueron registrados en el sector norte muchos de los motivos que no tienen parangón en otras localizaciones, principalmente, en aquellos sitios con la mayor diversidad de clases. En consecuencia, la mayor variedad de motivos podría vincularse con las localizaciones visitadas más reiteradamente aunque de forma efímera y, posiblemente separada por lapsos prolongados. Lo señalado da cuenta de una redundancia ocupacional específica y de la convergencia de ideas que estarían en circulación en la suprarregión del CVPA, algunas de las cuales podrían conectarse con áreas alejadas tales como la Meseta Central santacruceña -motivos de manos, mayoritariamente, y ampliación de las series tonales representadas, incluyendo tonos blancos, negros y ocres-. Por su parte, los sitios con diversidad y frecuencia bajas de motivos podrían reflejar formas diferentes de circulación conceptual y poblacional, en principio, menos intensas y tal vez más generalizada.
La menor representación de motivos exclusivos a ciertas localizaciones en el sector norte del CVPA es, tal como se dijo, acorde con la mayor diversidad existente. Una explicación podría apoyarse en que este sector se encuentra dentro de la unidad fisiográfica "Estepa Magallánica Húmeda", una de las más productivas del sur de Santa Cruz en función de la biomasa vegetal y animal (Borrelli et al. 1997). En relación con lo anterior, también debe mencionarse que la cuenca del río Gallegos muestra escasas dificultades para el tránsito, dada la amplitud del valle fluvial como la escasa altura alcanzada por las coladas basálticas.

Por otra parte, se ha sugerido un aumento poblacional en el extremo sur de Patagonia ocurrido después del 2500 AP (Borrero 2001; Massone 1984, entre otros), proceso que habría contribuido a una alta y tal vez más rápida dispersión de motivos/ideas. Lo señalado podría estar expresado en sitios tales como PEC y PCV, que registran mayor cantidad de diseños que pueden ser considerados "raros". Es posible que en estos lugares -al haber sido ocupados y/o transitados en forma redundante- la frecuencia de motivos aumente, hecho que a su vez incrementa las posibilidades de registrar -en esos sitios- clases menos frecuentes.

En la elección de espacios debieron pesar tanto las condiciones de habitabilidad que éstos brindan -factores internos- como los atractores que ejerce el entorno circundante sobre los grupos humanos -factores externos-. En consecuencia, se esperaría que las diversas condiciones que ofrecen los reparos rocosos también se reflejen en las frecuencias y densidades de motivos rupestres plasmados en ellos. No obstante, es posible que esta valoración varíe al ser conjugada con cuestiones tales como las características de los soportes, la proximidad con otras localizaciones con registro de ocupaciones humanas sin evidencias de pinturas rupestres y con la visibilidad de ese sector de la colada en relación con el espacio circundante (Manzi et al. 2010). En este sentido, el uso humano le imprime a esos espacios distintas clases de modificaciones que operan a favor de la construcción de nichos ecológicos (Odling y Smee 2003) al transformar las relaciones preexistentes entre los organismos que los habitan (Pianka 1978).

La circulación de información fue clave en la intensidad del uso otorgado a los espacios con manifestaciones rupestres. Esto se reconoce, por ejemplo, en la reutilización de un mismo lugar para 
plasmar motivos semejantes -MLB2-, en la superposición de motivos diferentes -PCV, PEC, ARB- y en el reciclado de otros -PEC-. En igual sentido, podría también expresarse la elección de las series tonales ejemplificada en la alternancia de los tonos bermellón y carmesí en los paredones 1 y 2 de PCV y, en las series negras y blancas y las bicromías utilizadas para ejecutar motivos poco frecuentes algunos de los cuales tienen una distribución espacial que exceden al CVPA.

Los espacios plásticos de representación fueron construidos a partir de soportes naturales con diferentes características (paredes, paredones, aleros y cuevas), extensiones y relaciones de continuidad. En algunos casos próximos a lugares de ocupación -ARB, PAA1, PAC1-, de cañadones -PCV y PEC-, bordes de coladas -ARB y AGA1- y a lo largo de extensas laderas -MLB1, MLB2 y MLB3-. Esta distribución de pinturas rupestres no puede ser atribuida al azar, sino que parece ser más acorde con una selección de lugares, puesto que no todo soporte potencialmente apto fue utilizado, pudiendo, quizás existir una planificación a largo plazo con incidencia en la continuidad de la producción pictórica y en la circulación y mantenimiento de información.

Cualquiera haya sido la función cumplida por las pinturas rupestres en las estrategias cazadoras recolectoras del extremo sur de Patagonia, es evidente que su producción es parte de un comportamiento reiterado que se trasmitió de generación en generación y cuya significación cultural podría vincularse con indicadores de vías o trayectos de movilidad y de contactos -evitado o buscado- entre poblaciones dispersas en espacios muy amplios.

\section{AGRADECIMIENTOS}

A los señores administradores de las Estancias Bella Vista, Héctor Grant, y Las Buitreras, Roberto Márquez Tau. Al personal del lodge de pesca de Estancia Las Buitreras, Srta. Fernanda Villagra y Sr. Claudio Martín. A Patricia Campan, quien es parte de este equipo de investigación y desarrolló distintas etapas de los trabajos de campo. A Juan Bautista Belardi por la lectura de una versión preliminar del manuscrito. Este trabajo se realizó en el marco del proyecto de investigación UARG-UNPA "Línea de base arqueológica en la cuenca del río Gallegos: su importancia para el desarrollo de un turismo sustentable" (29/A188) y 2010-12 Proyecto
PIP 1122009010020101 (2010-2012) “Arqueología distribucional de cazadores recolectores en el sector medio de la cuenca del río Gallegos, Santa Cruz". CONICET.

\section{BIBLIOGRAFÍA}

ASCHERO, C. y M. PODESTA. 1986. El arte rupestre en asentamientos Precerámicos de la Puna argentina. Runa XVI:29-57.

BATE, L. 1970. Primeras investigaciones sobre el Arte Rupestre de la Patagonia Chilena. Anales del Instituto de la Patagonia 1: 15-25.

BATE, L. 1971. Primeras investigaciones sobre el Arte Rupestre de la Patagonia Chilena (segundo informe). Anales del Instituto de la Patagonia 2: 33-41.

BORRELLI, P., G. OLIVA, M. WILLIAMS, L. GONZÁLEZ, P. RIAL y L. MONTES. 1997. Sistema regional de soporte de decisiones. Santa Cruz y Tierra del Fuego. Prodesar (Proyecto de Prevención y Control de la Desertificación en Patagonia (INTA-GTZ). EEA Santa Cruz. Río Gallegos.

BORRERO, L. 2001. El poblamiento de la Patagonia. Toldos, milodones y volcanes. Emecé Editores, Buenos Aires.

BORRERO, L. y L. MANZI. 2007. Arqueología supra-regional y biogeografía en la Patagonia Meridional. Levantando piedras, desenterrando huesos... y develando arcanos. Ediciones CEQUA. pp:163-172. Punta Arenas.

CAMPAN, P.; F. CARBALLO MARINA y L. MANZI 2007. Arqueología de Estancia La Carlota (Campo volcánico Pali Aike, Argentina). En: Levantando piedras, desenterrando huesos... y develando arcanos. Ediciones CEQUA. pp:687-699. Punta Arenas.

CARBALLO MARINA, F., MANZI, L., CAMPAN, P., BELARDI, J., TIBERI, P., MANERO, A. y J. SÁENZ 2008. Distribución del registro arqueológico en la cuenca del río Gallegos (provincia de Santa Cruz): Línea de base y aporte a la preservación del patrimonio. Arqueología del extremo sur del continente americano. Resultados de nuevos proyectos. Editado por Borrero, L. y N. Franco. Editorial Dunken. pp:175:225. Buenos Aires.

CARDEN, N. 2008. Imágenes a través del tiempo. Arte rupestre y construcción social del paisaje en la Meseta Central de Santa Cruz. Sociedad Argentina de Antropología. Colección Tesis Doctorales. Buenos Aires.

CORBELLA, H. 2002. El campo volcánico-tectónico de Pali Aike. Geología y Recursos Naturales de Santa Cruz. Relatorio del XV $\mathrm{V}^{\circ}$ Congreso Geológico Argentino. Editado Haller, M. pp:287-303. El Calafate. 
D’ORAZIO, M., AGOSTINI, F. MAZZARINI, P., INNOCENTI, M., MANETTI, M., HALLER J. y A. LAHSEN. 2000. The Pali Aike Volcanic Field, Patagonia: Slab-Window Magmatism Near The Tip of South America. Tectonophysics 321:407-427.

GALLARDO, F. 2009. Sobre la composición y la disposición en el arte rupestre en Chile: consideraciones metodológicas e interpretativas. Magallania 37(1):85-98.

GOMEZ OTERO, J. 1983-85. Investigaciones arqueológicas en las cuencas media y superior del río Gallegos. Informe Final Beca de Perfeccionamiento CONICET. Buenos Aires. MS.

GOMEZ OTERO, J. 1988. Investigaciones binacionales en la zona fronteriza argentino-chilena (paralelo $52^{\circ} \mathrm{S}$ ), entre el valle del Río Chico y del Gallegos Chico. Informe CONICET. Buenos Aires. MS.

GÓMEZ OTERO, J. 1989-90. Cazadores tardíos en la zona fronteriza del paralelo $52^{\circ}$ sur. El paraje de Juni Aike. Anales del Instituto de la Patagonia 19:47-71.

GÓMEZ OTERO, J. 1993. The Function of Small Rockshelters in the Magallanes IV Phase Settelments System (South Patagonia). Latin American Antiquity 4:325-345.

HERNÁNDEZ LLOSAS, M. I., H. NAMI y M. CUADRADO WOROSZYLO 1999. II-Resultados preliminares sobre las representaciones rupestres. Praehistoria 3:202-217.

L'HEUREUX, L. La arqueofauna del Campo Volcánico Pali Aike. El sitio Orejas de Burro 1, Santa Cruz, Argentina. Magallania 36(1):65-78.

MAERZ, J. y P. MORRIS. 1930. A dictionary of color. Mc Graw Hill. New York.

MANZI, L., F. CARBALLO MARINA y P. CAMPAN 2010. Manifestaciones rupestres y distribuciones artefactuales en el campo volcánico Pali Aike (sector medio del río Gallegos, Santa Cruz): nuevas evidencias arqueológicas. Actas del XVII Congreso Nacional de Arqueología Argentina. pp:80-86. Mendoza.

MITHEN, S. 1996. The Origin of Art. Natural Signs, Mental Modularity, and Visual Symbolism. Darwinian Archaeologies, editado por Herbert Donald Graham Maschner. Plenum Press. pp:197-217. New York.

MASSONE, M. 1982. Nuevas investigaciones sobre el arte rupestre de Patagonia meridional chilena. Anales del Instituto de la Patagonia 13:73-94.

MASSONE, M. 1984. Los paraderos tehuelches y prototehuelches en la costa del estrecho de Magallanes. Anales del Instituto de la Patagonia 15:27-43.

MASSONE, M. 1985. Estudio comparativo de nuevos sitios con pinturas rupestres aborígenes de Magallanes. Simposio de Estudios de arte rupestre - Primeras jornadas de
Arte y Arqueología. Editores Aldunate, C.; Berenguer, J. y V. Castro. Museo chileno de Arte Precolombino. pp:205-224, Santiago.

MEGLIOLI, A. 1992. Glacial Geology and Geochronology of Southernmost Patagonia and Tierra del Fuego, Argentina and Chile. Tesis Doctotal. University of Lehigh. MS.

MOLINA, M. 1972. Nuevos Aportes para el Estudio del Arte Rupestre Patagónico. Anales de la Universidad de la Patagonia San Juan Bosco. Ciencias Antropológicas, Tomo I(4):64-182. Comodoro Rivadavia.

ODLING-SMEE, F., LALAND, K. y M. FELDMAN. 2003. Niche construction. The neglected process in evolution. Princeton University Press. Princeton.

ORTIZ TRONCOSO, O. 1973. Artefactos de sílex de una tumba de Morro Philippi, valle medio del Río Gallegos. Anales del Instituto de la Patagonia 2(IV-2):1-3.

PIANKA, E. 1978. Ecología Evolutiva. Ediciones Omega. Barcelona.

PRIETO, A. 1984. Hallazgo de un colgante decorado en Morro Chico (Magallanes). Anales del Instituto de la Patagonia 15:59-61.

PRIETO, A., MORELlO, F., CÁRDENAS, R. y M. CHRISTENSEN. 1998. Cañadón Leona: A sesenta años de su descubrimiento. Anales del Instituto de la Patagonia 26:81-105.

SANGUINETTI DE BORMIDA, A. 1981. Introducción a la Prehistoria de la Patagonia Argentina. UBA, Facultad de Filosofía y Letras. Tesis de Doctorado. Buenos Aires. MS. SAN ROMÁN M., F. MORELLO y A. PRIETO 2000. Cueva de los Chingues (Parque Nacional Pali Aike), Magallanes, Chile. Historia Natural y Cultural I. Anales del Instituto de la Patagonia 28:125-146.

SEPULVEDA, M. 2011. Pinturas rupestres y tecnología del color en el extremo sur de Chile. Magallania 39(1):193-210.

SHENNAN, S. 2000. Population, Culture History, and Change. Current Anthropology 41: 811-835.

SKEWES, M. 1978. Geología, petrología, quimismo y origen de los volcanes del área de Pali-Aike, Magallanes, Chile. Anales del Instituto de la Patagonia 9:95-106.

STERN, N. 1994. The Implications of Time-Averaging for Reconstructing the Land-use Patterns of Early Tool-using Hominids. Early Hominid Behavioral Ecology. Editado por Oliver, J., Sikes, N. y K, Steart, Academic Press. pp:89-105. New York.

THOMAS, D. 1975. Nonsite Sampling in Archaeology: Up the Creek Without a Site? Sampling in Archaeology. Editado por James, W. The University of Arizona Press. pp:61-83. Tucson. 